\title{
Discrimination of coated carbide tools wear by the features extracted from parallel force and noise level
}

\author{
Wayan DARMAWAN ${ }^{\mathrm{a}, \mathrm{b} *}$, Chiaki TANAKA ${ }^{\mathrm{c}}$ \\ a Faculty of Forestry, Bogor Agricultural University, Kampus IPB Darmaga, Bogor 16680, Indonesia \\ b Current address: Dept. Teknologi Hasil Hutan, Fakultas Kehutanan, Kampus IPB Darmaga, Bogor 16680, Indonesia \\ ${ }^{c}$ Faculty of Science and Engineering, Shimane University, Nishikawatsu-cho 1060, Matsue, Shimane 690-8504, Japan
}

(Received 27 February 2003; accepted 2 July 2004)

\begin{abstract}
Coated carbide tools were tested for turning of wood-chip cement board. Coating materials, which were synthesized on the P30 carbide substrate, are titanium carbonitride, titanium nitride, chromium nitride, and titanium nitride/aluminum nitride. Cutting tests were performed at cutting speeds of 30, 40, 50 and $60 \mathrm{~m} / \mathrm{s}$, depth of cut of $1 \mathrm{~mm}$, and feed of $0.05 \mathrm{~mm} / \mathrm{rev}$. Wear, parallel force and noise level were measured at every specified cutting length. The purpose was to discriminate various stages of wear of the coated carbide tools by the features extracted from parallel force and noise level. The results of the study show that both the parallel force and noise level generated by the tools tested were observed to increase linearly with increasing the tools wear, and would be good parameters for monitoring the tool wear. The parallel force and the noise level of the cutting tools also increased with increasing the cutting speeds for every specified cutting length. The parallel force became more sensitive than the noise level for monitoring the tool wear when the cutting speed was increased.
\end{abstract}

coated carbide tool / parallel force / noise level / wood-chip cement board / cutting speed

Résumé - Estimation de l'usure d'outils carbures revêtus à partir de paramètres extraits de l'analyse du bruit et des efforts de coupe. Des outils carbure ont été testés dans un essai de tournage de panneaux bois ciment. Le carbonite, de titane, le nitride de titane, le nitride de chrome et le complexes nitride de titane/nitride d'aluminium ont été utilisés comme matériaux de revêtement sur un substrat carbure de type P30. Les essais de coupe ont été réalisés à des vitesses de 30, 40, 50 et $60 \mathrm{~m} / \mathrm{s}$ avec une profondeur de coupe de $1 \mathrm{~mm}$ et une avance de $0,05 \mathrm{~mm}$ par tour. L'usure, la composante de l'effort de coupe parallèle au mouvement relatif bois/outil et le niveau de bruit ont été menés pour chaque longueur de coupe retenue. L'objectif était de distinguer différentes étapes d'usure de l'outil revêtu à partir de l'analyse des signaux d'efforts et de bruit. L'étude a montré que la composante parallèle de l'effort de coupe et le niveau de bruit augmentaient tous deux de manière linéaire avec l'usure mesurés sur la face de dépouille, pour tous les outils testés. Ce sont potentiellement de bons paramètres pour le suivi en ligne de l'usure de l'outil. Ces deux paramètres augmentent aussi quand la vitesse de coupe augmente, pour toutes les longueurs de coupes utilisées. La composante parallèle de l'effort de coupe devient un paramètre plus sensible pour suivre l'usure de l'outil quant la vitesse de coupe augmente.

outil carbure revêtu / effort de coupe / niveau de bruit / composite bois ciment / vitesse de coupe

\section{INTRODUCTION}

Some automatic monitoring systems have been proposed to achieve a higher productivity in wood processing. Application of the automatic monitoring system in band-sawing, circularsawing, routing, milling and peeling would help the wood worker in increasing productivity, diagnosing the machine conditions (bearings, chains), predicting the machining imperfectness (washboard, abnormal roughness), and controlling the cutting tool condition (tool edge wear, tool edge damage). Several parameters (cutting energy [10], cutting force [6], cutting sound [15], acoustic emission [8], saw vibration [9], cutting temperature [11]) were investigated to be useful for providing information to the automatic systems.

Cutting tools are generally replaced or grinded to minimize the probable consequences of a failure event during the cutting processes. A wood worker may check or replace the cutting tool frequently to reduce the probability of an in-process failure, but as a consequent interrupting the process so frequently is a decrease in productivity and an increase in tool cost. Though a skilled worker in woodworking industry can diagnose the state of tool wear during the cutting processes by the cutting force, cutting noise, or cutting power consumption with the help of his experiences, however recently, due to the lack of those skilled workers and the increasing demands for the production techniques for higher efficiency and productivity, it is necessary to promote an automation in the woodworking industry. For the realization of the automatic mechanical processing of wood, the in-process monitoring and the diagnosing of the process is an important technique to be developed.

Cutting forces and noise level have shown great promise in the monitoring of the extent of tool wear. An excellent correlation

\footnotetext{
* Corresponding author: wayandar@indo.net.id
} 
Table I. Specifications of the coated carbide tools.

\begin{tabular}{lcccc}
\hline Cutting tool & $\begin{array}{c}\text { Thickness } \\
\text { of film }(\mu \mathrm{m})\end{array}$ & Hardness $(\mathrm{HV})$ & $\begin{array}{c}\text { Resistance to oxidation } \\
\text { temperature }\left({ }^{\circ} \mathrm{C}\right)\end{array}$ & $\begin{array}{c}\text { Absorptive capacity of heat energy } \\
\left.(\mathrm{Ws})^{1 / 2} / \mathrm{m}^{2} \mathrm{~K}\right)\end{array}$ \\
\hline P30 carbide & - & 1450 & - & - \\
TiN coated P30 & $3-4$ & 2000 & 750 & 8100 \\
CrN coated P30 & $3-4$ & 1800 & 800 & - \\
TiCN coated P30 & $3-4$ & 3000 & 450 & 13900 \\
TiN/AlN coated P30 & $3-4$ & 4000 & 930 & 6300 \\
\hline
\end{tabular}

Table II. Specifications of the wood-chip cement board.

\begin{tabular}{lc}
\hline Thickness $(\mathrm{mm})$ & 25 \\
Density $\left(\mathrm{g} / \mathrm{cm}^{3}\right)$ & 1.20 \\
Moisture content $(\%)$ & 11.6 \\
Compressive strength $\left(\mathrm{N} / \mathrm{mm}^{2}\right)$ & 23.4 \\
Shear strength $\left(\mathrm{N} / \mathrm{mm}^{2}\right)$ & 3.5 \\
Hardness $\left(\mathrm{N} / \mathrm{mm}^{2}\right)$ & 50.6 \\
Composition & \\
$\quad$ Wood-chip & $25 \mathrm{wt} \%$ \\
$\quad$ Cement & $75 \mathrm{wt} \%$ \\
\hline
\end{tabular}

was found to exist between the cutting forces and tool wear [1, $13,14]$, and the feasibility of techniques of pattern recognition using the cutting sound for the discrimination of the various stages of edge wear was clarified [7]. Another study revealed that behavior of acoustic emission (AE) signal was found to be a superior parameter for estimation of wear of the cutting tool [12]. In those studies, non-coated tools with their various geometries were experimented.

In another study, coated carbide tools were experimented for cutting wood based materials, and their wear characteristics were reported [3-5]. In an effort to provide more information, the parallel force and noise level of the tools, and their changes due to the wear were reported in this paper. The regression equations were applied to discriminate the various stages of tool wears by the features extracted from the parallel force and noise level. The purpose is to determine the feasibility of using parallel force and noise level to monitor the extent of wear of the coated carbide tools for various cutting speed.

\section{MATERIALS AND METHODS}

\subsection{Coated carbide tools and work material}

Specifications of coated carbide tools tested, work material machined and cutting conditions applied are summarized in Table I, Table II, Table III respectively. P30 carbide tool [81\% WC, $9 \%$ (Ti,Ta), $10 \% \mathrm{Co}$ ] used as a substrate was in $12.7 \mathrm{~mm}$ long, $12.7 \mathrm{~mm}$ wide, and $4.8 \mathrm{~mm}$ thick. Some P30 carbides were coated with the single layer of titanium nitride (TiN), chromium nitride $(\mathrm{CrN})$, titanium carbonitride (TiCN) and alternating-multilayer of titanium nitride/aluminum nitride (TiN/AIN) coatings by PVD method on the rake and clearance faces. All the coated tools were produced in a standard production line for experiment.
Table III. Cutting conditions for the carbide tools.

\begin{tabular}{lc}
\hline Cutting speed (V) & $30,40,50,60 \mathrm{~m} / \mathrm{s}$ \\
Feed (F) & $0.05 \mathrm{~mm} / \mathrm{rev}$ \\
Depth of Cut (D) & $1.0 \mathrm{~mm}$ \\
Tool geometry & \\
$\quad$ Wedge angle & $90^{\circ}$ \\
Corner radius & $0.8 \mathrm{~mm}$ \\
\hline
\end{tabular}

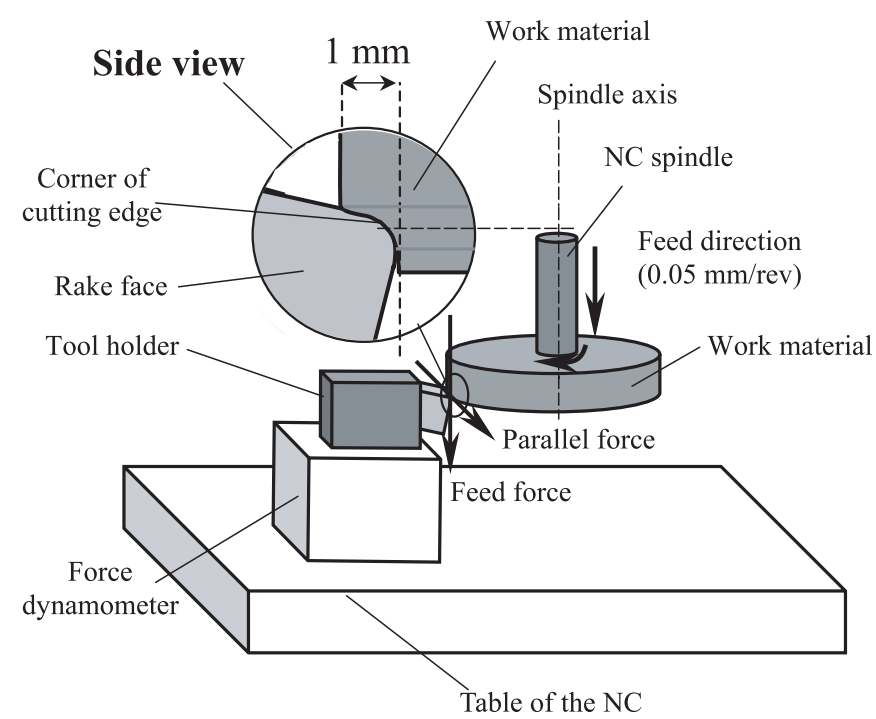

Figure 1. Schematic diagram of the turning test.

\subsection{Methods}

Wear resistance of the coated carbide tools was tested in turning high-density wood-chip cement board. Schematic diagram of the turning tests is presented in Figure 1. In the figure, wood-chip cement board in diameter of $300 \mathrm{~mm}$ was held on the router spindle of numerical controlled (NC) machine. A tool with its holder, which was designed to produce cutting angle of $-5^{\circ}$ and clearance angle of $5^{\circ}$, was placed on the three component forces of dynamometer that was held on the table of the NC machine.

Turning was performed by the corner of the cutting edge along the edge of the disk (work material) with depth of cut of $1 \mathrm{~mm}$. The disk was fed down into the corner of the cutting edge in the speed of $0.05 \mathrm{~mm} / \mathrm{rev}$. When the cutting tools finished one pass of cutting (cutting from bottom face to top face of the disk with cutting length of about $500 \mathrm{~m}$ ), the amount of clearance wear on the corner of the cutting 


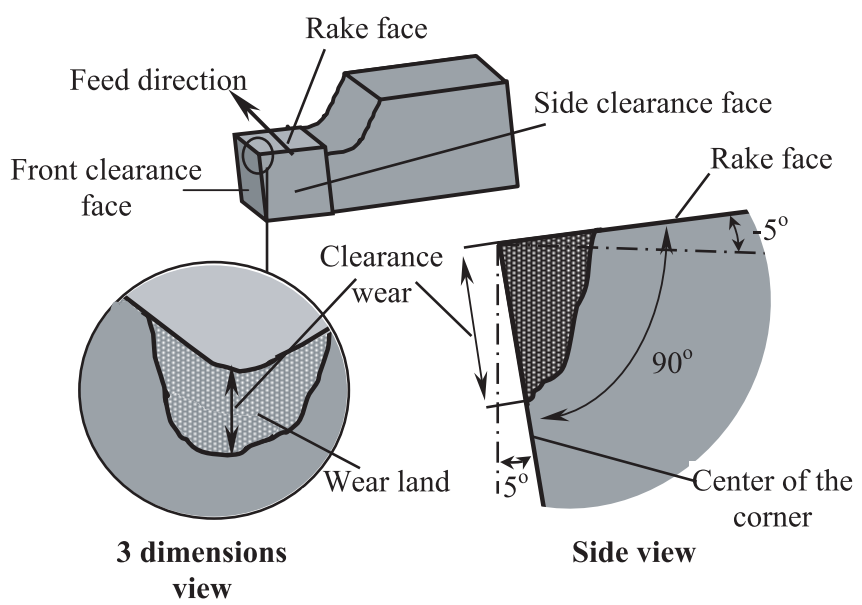

Figure 2. Illustration of clearance wear measurement.

edge, parallel force and noise level were measured. Then, cutting test was continued on another new disk by replacing the old disk with the new disk. Testing was stopped up to ten pass of cutting (cutting length of about $5 \mathrm{~km}$ ).

\subsection{Measurements}

All tools were inspected before testing to assure that there are no surface cracks and chippings of the coating materials on the clearance face using an optical video microscope. Measurement of the wear was made using a measure-microscope as shown in Figure 2. The tools were also inspected at the final cut using an optical-video microscope and a scanning electron microscope/energy dispersive spectroscopy (SEM/EDS) for identification of the mode of the cutting edge failure and mapping the residuals elements of the worn surfaces.

A precision Sound Level Meter was used for measurement of the sound level of the audible cutting noise on the $\mathrm{C}$ weighting, which is usually used for measuring the peak of sound pressure level. The Sound Level Meter was connected to a microphone, which was set up at the height of the cutting tool edge (about $1000 \mathrm{~mm}$ above ground level) and at a distance of about $1000 \mathrm{~mm}$ along a straight line extending from the cutting tool edge.

Measurement of the parallel force was made by using the three components force of dynamometer attached on the table of the NC machine. The three components force of dynamometer was connected to a strain amplifier and a GP-IB board was used to record and to display the force during cutting on the personal computer.

\section{RESULTS AND DISCUSSION}

\subsection{Parallel force and noise characteristics of the coated carbide tools with clearance wear}

The experimental results indicated that all tools tested show the same behavior in relationship between parallel force and clearance wear, and noise level and clearance wear for all cutting speeds performed. For this discussion, the parallel force and noise level behaviors of the TiN/AlN coated tool are provided as presented in Figures 3 and 4. These figures give an indication that the parallel force and the noise level generated

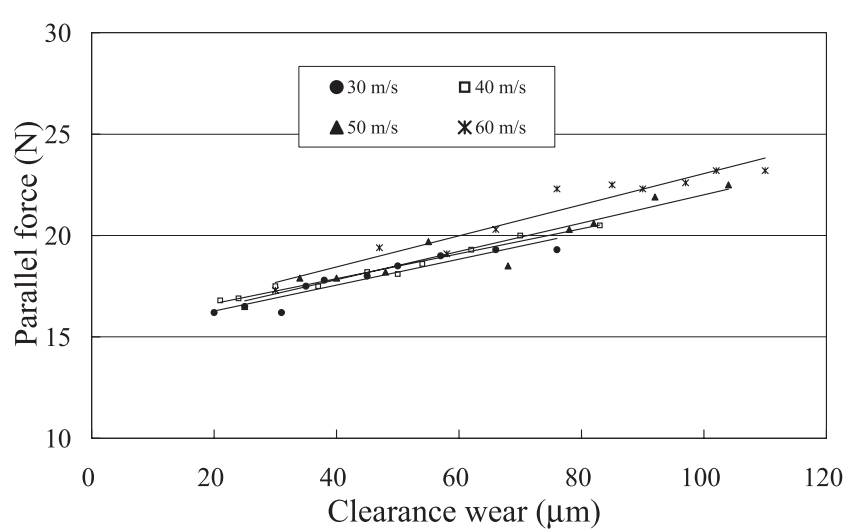

Figure 3. Linear relationships between parallel force and clearance wear of the TiN/AIN coated tool for various cutting speeds.

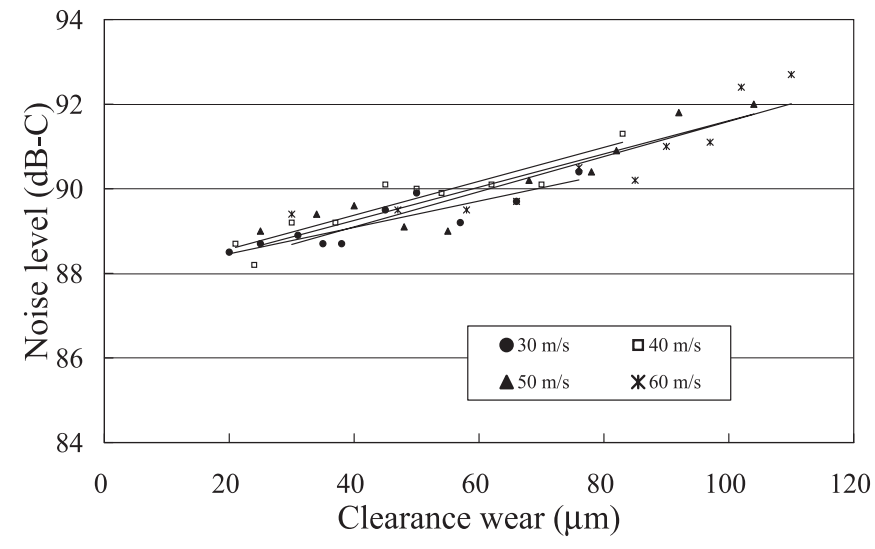

Figure 4. Linear relationships between noise level and clearance wear of the TiN/AlN coated tool for various cutting speeds.

by the tools increased linearly with an increase in the clearance wear.

Regression equation and its correlation coefficient for the linears in Figures 3 and 4 are summarized in Table IV. The regression equations and correlation coefficients for the other tools are also included in Table IV for comparison. The results show that the regression coefficients for the parallel force linears depicted by the tools vary from 0.04 to 0.08 , and for the noise level vary from 0.02 to 0.04 . These variations give an indication that the tool materials (coating materials) determined the rate of the increase of the parallel force and the noise level. It appears that TiN coated tool would be more gradual in the increase of the parallel force compared to the others, which would be almost the same in the rate of the increase (Tab. IV). The TiN/AlN coated tool would be more abrupt in the increase of the noise level compared to the others. However, the regression coefficients for the parallel force and noise level among cutting speeds in each tool are almost the same. This means that each tool would generate almost the same parallel force and noise level as long as the amounts of clearance wear attained are the same. 
Table IV. Regression equation and correlation coefficient for the relationship between parallel force, noise level and clearance wear.

\begin{tabular}{|c|c|c|c|c|c|}
\hline \multirow[t]{2}{*}{ Cutting tools } & \multirow[t]{2}{*}{ Cutting speed $(\mathrm{m} / \mathrm{s})$} & \multicolumn{2}{|c|}{ Parallel force and clearance wear } & \multicolumn{2}{|c|}{ Noise level and clearance wear } \\
\hline & & Linear equation & $r$ & Linear equation & $r$ \\
\hline \multirow{4}{*}{ P30 carbide } & 30 & $Y=9.38+0.08 X$ & 0.97 & $\mathrm{Y}=83.37+0.03 \mathrm{X}$ & 0.94 \\
\hline & 40 & $\mathrm{Y}=12.46+0.08 \mathrm{X}$ & 0.92 & $Y=86.41+0.02 X$ & 0.96 \\
\hline & 50 & $\mathrm{Y}=12.68+0.07 \mathrm{X}$ & 0.96 & $Y=86.02+0.02 X$ & 0.92 \\
\hline & 60 & $\mathrm{Y}=11.13+0.06 \mathrm{X}$ & 0.95 & $\mathrm{Y}=86.79+0.02 \mathrm{X}$ & 0.91 \\
\hline \multirow[t]{4}{*}{ TiN/AlN coated } & 30 & $Y=15.00+0.06 X$ & 0.94 & $\mathrm{Y}=87.80+0.03 \mathrm{X}$ & 0.89 \\
\hline & 40 & $Y=15.03+0.06 X$ & 0.96 & $\mathrm{Y}=87.77+0.04 \mathrm{X}$ & 0.90 \\
\hline & 50 & $\mathrm{Y}=15.03+0.07 \mathrm{X}$ & 0.95 & $Y=87.68+0.04 X$ & 0.92 \\
\hline & 60 & $\mathrm{Y}=15.38+0.08 \mathrm{X}$ & 0.96 & $\mathrm{Y}=87.44+0.04 \mathrm{X}$ & 0.89 \\
\hline \multirow[t]{4}{*}{$\mathrm{CrN}$ coated } & 30 & $\mathrm{Y}=14.33+0.06 \mathrm{X}$ & 0.87 & $Y=84.35+0.03 X$ & 0.93 \\
\hline & 40 & $\mathrm{Y}=15.37+0.06 \mathrm{X}$ & 0.90 & $Y=86.67+0.02 X$ & 0.87 \\
\hline & 50 & $\mathrm{Y}=17.44+0.05 \mathrm{X}$ & 0.91 & $Y=86.95+0.02 X$ & 0.96 \\
\hline & 60 & $Y=16.70+0.06 X$ & 0.96 & $Y=87.06+0.02 X$ & 0.88 \\
\hline \multirow[t]{4}{*}{ TiN coated } & 30 & $Y=16.08+0.04 X$ & 0.77 & $\mathrm{Y}=85.74+0.03 \mathrm{X}$ & 0.89 \\
\hline & 40 & $Y=16.71+0.04 X$ & 0.89 & $Y=86.46+0.03 X$ & 0.92 \\
\hline & 50 & $\mathrm{Y}=19.78+0.05 \mathrm{X}$ & 0.79 & $Y=87.15+0.02 X$ & 0.87 \\
\hline & 60 & $\mathrm{Y}=18.48+0.04 \mathrm{X}$ & 0.97 & $\mathrm{Y}=87.21+0.02 \mathrm{X}$ & 0.87 \\
\hline \multirow[t]{4}{*}{ TiCN coated } & 30 & $Y=12.62+0.08 X$ & 0.90 & $Y=85.48+0.03 X$ & 0.88 \\
\hline & 40 & $\mathrm{Y}=15.53+0.07 \mathrm{X}$ & 0.97 & $Y=86.40+0.03 X$ & 0.90 \\
\hline & 50 & $Y=15.80+0.05 X$ & 0.93 & $Y=86.69+0.02 X$ & 0.98 \\
\hline & 60 & $\mathrm{Y}=15.28+0.06 \mathrm{X}$ & 0.92 & $Y=86.97+0.02 X$ & 0.94 \\
\hline
\end{tabular}

$\mathrm{Y}=$ parallel force and noise level, $\mathrm{X}=$ clearance wear, $r=$ correlation coefficient.

It also appears from the results in Table IV that both the parallel force and noise level are high in correlation coefficient with the clearance wear. Therefore, the variation in the parallel force and noise level with clearance wear is a good indication of the extent of wear on the clearance face.

\subsection{The effect of cutting speed on the parallel forces and noise level}

The experimental results indicated that the parallel force increased proportionally with an increase in cutting speed at every specified cutting length for all tools investigated. For this discussion, relation between parallel force and cutting speed for the final cutting length is provided in Figure 5. The increase in the parallel force with an increase in cutting speed was caused by larger relaxation of the work material on the clearance face [2] and greater amount of clearance wear [5], which further caused high rubbing pressure on the clearance surface of the coated carbide tools, being attained by the cutting tools for the high cutting speed.

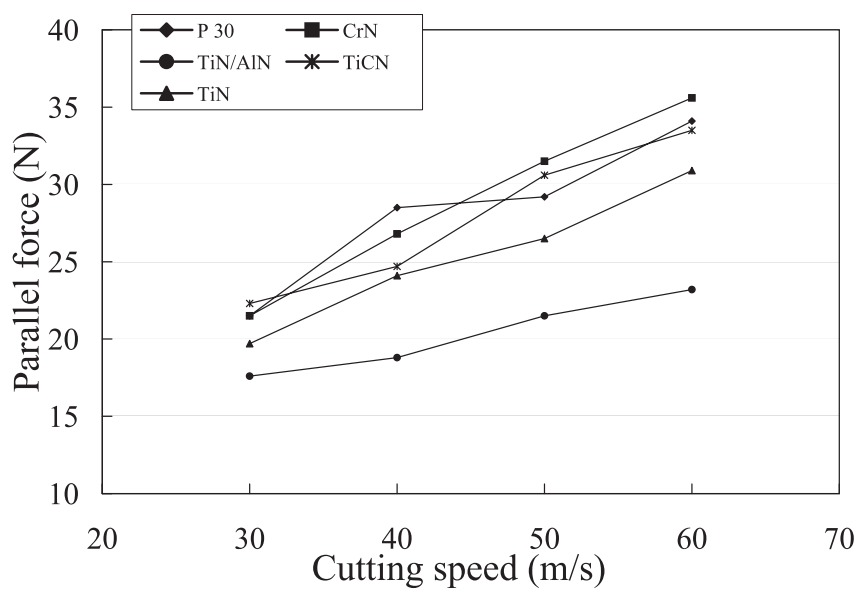

Figure 5. Behaviors of the parallel force of the tools tested with cutting speed for the final cutting length. 


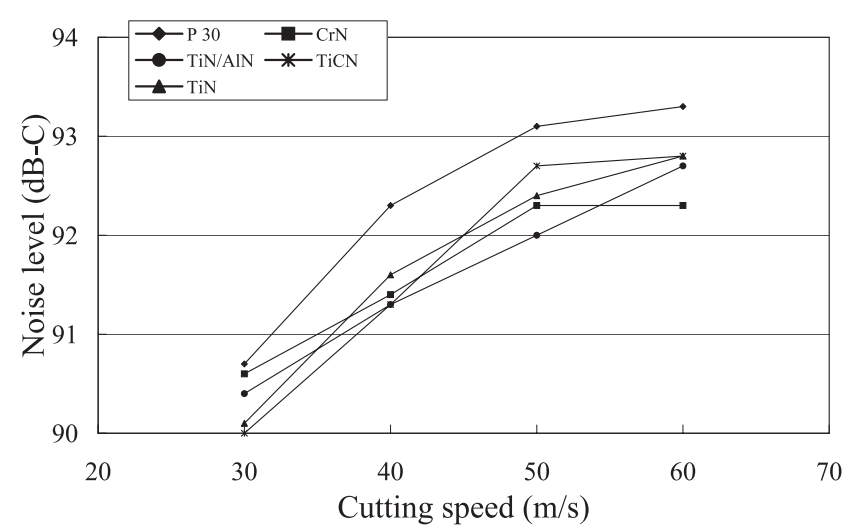

Figure 6. Behaviors of the noise level of the tools tested with cutting speed for the final cutting length.

Experimental results in Figure 5 show that the TiN/AlN coated carbide tool generated the smallest parallel force for all cutting speeds at the final cutting length among the tools investigated. This is considered to be due to the fact that the TiN/ AlN coated carbide tool suffered much lower amount of clearance wear at every cutting speed performed compared to the other tools investigated [5]. On the other hand the other tools investigated varied slightly in the parallel force as the cutting speed was increased.

The experimental results also indicated that the noise level generated by all tools increased proportionally with an increase in cutting speed for every specified cutting length. In Figure 6, the noise levels generated by all tools at the final cutting length are provided for this discussion. The high noise levels generated during high-speed cutting are probably caused by large impact force being imposed on the tools for the high-speed cutting. It is also observed from the results in Figure 6 that though the amount of clearance wear of the TiN/AlN coated carbide was much lower than the other tools investigated [5], however its noise level is almost the same as that of the other tools. This could be due to the extreme hardness of the TiN/AlN coated tool, which imposed large impact during the cutting.

\subsection{Relationship between parallel force and noise level}

The results in Figure 7 indicate that the noise level and the parallel force are close in relationship. The noise level increased linearly with increasing the parallel force. It could be considered from the regression equation in Figure 7 that the tools (in average) would generate about $1 \mathrm{~dB}$ noise level when the parallel force of the tools changed in $2 \mathrm{~N}$ for the 30,40 , and $50 \mathrm{~m} / \mathrm{s}$ cutting speeds, and would generate about $1 \mathrm{~dB}$ noise level when the parallel force changed in $4 \mathrm{~N}$ for the $60 \mathrm{~m} / \mathrm{s}$ cutting speed. This fact gives an indication that the parallel force became more sensitive compared to the noise level in determining the clearance wear behavior of the tools investigated when the cutting speed was increased.

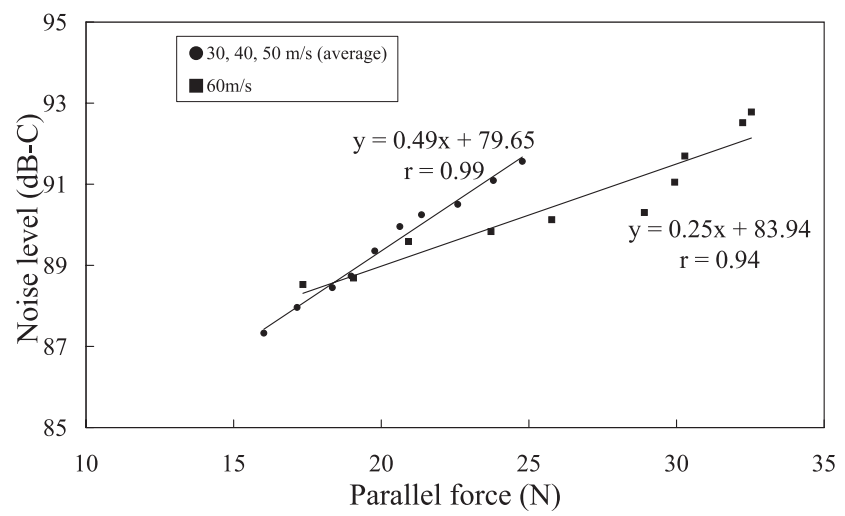

Figure 7. Linear relationships between noise level and parallel force of the tools investigated (in average) for $30,40,50 \mathrm{~m} / \mathrm{s}$ and $60 \mathrm{~m} / \mathrm{s}$ cutting speeds.

\section{CONCLUSIONS}

The following conclusions can be drawn based on the findings of this experiment.

1. Both the parallel force and noise level of the tools investigated increase with increasing the clearance wear, and would be a good indication for the extent of wear on cutting edge of the tools.

2. The tool materials (coating materials) are observed to determine the rate of the increase of the parallel force and the noise level.

3. Though the coated tools are applied for different cutting speed, the tools generate almost the same parallel force and noise level, as long as their amount of clearance wears are same.

4. The parallel force of TiN/AIN coated carbide tool are the smallest among the tools investigated, however its noise level is almost the same as that of the other tools investigated for every specified cutting length.

5. The parallel force becomes more sensitive than the noise level for monitoring the tool wear when the cutting speed is increased.

\section{REFERENCES}

[1] Axelsson B.O.M., Grundberg S.A., Gronlund J.A., Tool wear when planning and milling, Measurement methodology and influencing factors, in: Proceedings of the 11th International Wood Machining Seminar, 1993, pp. 159-176.

[2] Costes J.P., Larricq P., Towards high cutting speed in wood milling, Ann. For. Sci. 59 (2002) 857-865.

[3] Darmawan W., Tanaka C., Usuki H., Ohtani T., Wear characteristics of some coated carbide tools when machining hardboard and wood-chip cement board, J. Wood Ind. 55 (2000) 456-460.

[4] Darmawan W., Tanaka C., Usuki H., Ohtani T., Performance of coated carbide tools in grooving wood-based materials: Effect of coating materials and work material on the wear resistance of coated carbide tools, J. Wood Sci. 47 (2001) 94-101. 
[5] Darmawan W., Tanaka C., Usuki H., Ohtani T., Performance of coated carbide tools in turning wood-based materials: Effect of coating materials and cutting speeds on the wear characteristics of coated carbide tools in turning wood-chip cemenboard, J. Wood Sci. 47 (2001) 342-349.

[6] Eyma F., Meausoone P.J., Martin P., Study of the properties of thirteen tropical wood species to improve the prediction of cutting forces in modes B, Ann. For. Sci. 61 (2004) 55-64.

[7] Fujii Y., Fuketa T., Arashi Y., Okumura S., Noguchi M., Pattern recognition of cutting sound from woodworking tools and its application to the in-process monitoring of wear, in: Proceedings of the 11th International Wood Machining Seminar, 1993, pp. 147-156.

[8] Lemaster R., Tee L., Monitoring tool wear during wood machining with acoustic emission, Wear 101 (1985) 273-282.

[9] Ulsoy A.G., Mote C.D. Jr, Vibration of wide band saw blades, J. Engin. Ind. Trans. ASME 104 (1982) 71-78.

[10] Piotr I., Tanaka C., Energy Balance during orthogonal machining of medium density fiberboard, in: Proceedings of the 16th International Wood Machining Seminar, 2003, pp. 459-467.
[11] Sokojowski W., Gogolewski P., Temperature of machined surface as value for tool condition monitoring during wood products milling, in: Proceedings of the 14th International Wood Machining Seminar, 1999, pp. 775-780.

[12] Tanaka C., Nakao T., Nishino Y., Hamaguchi T., Takahashi A., Detection of wear degree of cutting tool by acoustic emission signal, Mokuzai Gakkaishi 38 (1992) 841-846.

[13] Tanaka C., Takahashi A., Shiota Y., Cutting performance of cermet, ceramic, CBN and artificial diamond. I. Wear from continuous cutting of wood-based materials, Mokuzai Gakkaishi 32 (1986) 96102.

[14] Tanaka C., Takahashi A., Date H., Nakao T., Cutting performance of cermet, ceramic, CBN and artificial diamond. III. Cutting performance of ceramic tools, Mokuzai Gakkaishi 34 (1986) 298-304.

[15] Ying-jie Q., Zhao-hao Z., Xiao-jie Q., Shou-qian C., Li Z., Noise measuring and analysis study of precision panel saw, in: Proceedings of the 16th International Wood Machining Seminar, 2003, pp. 696-701 